\title{
Embedding Critical Thinking in IS Curricula
}

\author{
Theda Thomas, Tim Davis, and Alanah Kazlauskas \\ Australian Catholic University, Australia
}

\author{
theda.thomas@acu.edu.au,timothy.davis@acu.edu.au, \\ alanah.kazlauskas@acu.edu.au \\ Executive Summary
}

It is important for students to develop critical thinking and other higher-order thinking skills during their tertiary studies. Along with the ability to think critically comes the need to develop students' meta-cognitive skills. These abilities work together to enable students to control, monitor, and regulate their own cognitive processes and improve their ability to comprehend and solve problems.

This paper proposes the use of scaffolding as a method of helping students to develop their critical thinking and meta-cognitive skills within the IS curriculum. Scaffolding enables students to undertake tasks that they might not have been able to tackle without the scaffolding. It allows the learners to focus on the aspects of the task that they can manage, while still keeping an understanding of the task as a whole. As the scaffolding is gradually removed, the student should be able to work more independently and apply the new skills effectively.

The paper shows how the scaffolding of the process of critical thinking can be used in the early stages of the IS curriculum to enable students to first learn, then gain confidence, in using the techniques that they need to apply independently in the latter stages of the curriculum. Some of the topics covered and where skills were developed included writing essays (in particular essays that include argument), critical and analytical thinking in programming, and the use of problemsolving techniques in systems analysis and design.

In the section on critical and analytical thinking in programming, we show how we taught students to think logically and then how this was applied in programming. The task of testing algorithms was scaffolded to enable the students to learn how to evaluate a program and create test data. The paper then shows how the lecturer developed students' meta-cognitive skills by phrasing SQL questions that made the students conscious of their thinking and helped them to link what they were currently doing with their previous knowledge.

The paper goes on to show how the conventional problem-solving techniques that are often taught to school children can be used in systems analysis and design. These techniques help the student

Material published as part of this publication, either on-line or in print, is copyrighted by the Informing Science Institute.

Permission to make digital or paper copy of part or all of these works for personal or classroom use is granted without fee provided that the copies are not made or distributed for profit or commercial advantage AND that copies 1) bear this notice in full and 2) give the full citation on the first page. It is permissible to abstract these works so long as credit is given. To copy in all other cases or to republish or to post on a server or to redistribute to lists requires specific permission and payment of a fee. Contact Publisher@InformingScience.org to request redistribution permission. to consider the whole picture and to understand the relationships between the different parts of the system and how it interacts with the rest of the world.

Lastly, the paper describes how the students were taught to write and argue when writing an academic essay. The first assessment task was carefully scaffolded to help the students understand the need to put forward an argument, substantiate that argument and to mini- 
mize plagiarism. The scaffolding was once again removed to enable students to write without the help by their third year.

Keywords: critical thinking, higher-order thinking skills, IS curriculum, scaffolding

\section{Introduction}

Critical thinking is seen by some (Fagin, Harper, Baird, Hadfield \& Sward, 2006) as "the cornerstone of academic maturity and a trademark of a well-educated person." The IS 2002 curriculum requires "an embedded problem solving and critical thinking for all courses" (Gorgone et al., 2002, p. iv). What is critical thinking? How do we go about integrating critical thinking throughout an Information Systems course? Can we assume that if we give students problems to solve they will have the skills needed to solve them? Can we assume that students have the skills necessary to critically analyse written work and write effectively themselves? Can we assume that they are able to evaluate their own work and the work of others effectively?

Critical thinking has been defined as "the ability to think clearly and logically and to detect errors and fallacies in the thinking of others" (Jones, 1997). Some see it as problem solving, reasoning or higher-order thinking. Ayersman and Reed (1995-1996) describe critical thinking as the use of thinking skills to focus and adjust one's thinking to an appropriate form of thinking and, as a consequence, develop traits such as integrity and confidence in one's thinking. Critical thinking enables graduates to examine issues, establish relationships where appropriate, construct arguments, recognise and respect diverse perspectives, view phenomena from different points of view, and have the flexibility to restructure their thinking when reason leads them to do so.

The fact that universities are being called upon to develop students' critical thinking abilities underlines an assumption that students do not arrive at university with these skills. This paper will demonstrate that carefully scaffolded tasks in the first year, reinforced through the gradual transfer of responsibility for scaffolding from teacher to student in subsequent years, enables students to work at the higher-levels of Bloom's Taxonomy (Bloom, Englehart, Furst, Hill and Krathwohl, 1956) from the first year of their university experience. Given such a foundation, we can then expect students to begin to develop the independent ability to work at the higher levels of evaluating and creating because we have progressively developed their skills to work at these levels. This approach is also supported by Pascarella and Terenzini (1991) who found in studying the affect of tertiary studies on students, that formal critical thinking and reasoning skills improved just over 10 percentile points on average over the period of their studies and that, of particular note, approximately 85 percent of this improvement occurred during the freshman year (first year) of their studies (Pascarella \& Terenzini, 1991, p.118).

The problem for tertiary educators is how to foster and develop these skills in our students. Is it possible through our teaching, activities, and assessments to help students develop these complex higher-order thinking skills? We believe so.

This paper considers the need for students to develop their metacognitive skills in order to develop their higher-level order thinking skills. Scaffolding as a teaching method to help students learn to think critically is then described. The paper discusses the implementation of a foundation subject in reasoning and critical thinking in an ICT program. The examples used will be those from the Australian Catholic University (ACU National) where a subject called Reasoning and Critical Thinking for IS Professionals was introduced into the curriculum in 2003. The paper shows how scaffolding in the early years of the degree can be removed at later years to create independent learners. 


\section{Bloom's Revised Taxonomy and the Need for Metacognitive Skills}

The IS 2002 curriculum uses Bloom's taxonomy in its recommendation for handling depth of knowledge and higher-order thinking skills. As knowledge is moved from awareness through to advanced knowledge, Bloom's levels of knowledge go from knowledge recognition, comprehension and application through to analysis, synthesis and evaluation. Table 1 is reproduced from the IS2002 curriculum and outlines activities that can be done at each level (Gorgone et al., 2002, p.39).

Table 1: Knowledge levels, templates for objective writing and meaning of the depth levels with associated learning activities (Reproduced from Gorgone, et al., 2002, p.39)

\begin{tabular}{|c|c|c|c|}
\hline $\begin{array}{l}\text { IS '90, '94, '95, } \\
\text { '97, 2002 } \\
\text { Depth of } \\
\text { Knowledge }\end{array}$ & $\begin{array}{l}\text { Blooms Levels of } \\
\text { Knowledge }\end{array}$ & $\begin{array}{l}\text { Template for writing behav- } \\
\text { ioural objectives. Students } \\
\text { completing .... will be able to: }\end{array}$ & $\begin{array}{l}\text { Meaning of depth of knowledge level and } \\
\text { activities associated with attaining that } \\
\text { level }\end{array}$ \\
\hline \multicolumn{4}{|l|}{0 No Knowledge } \\
\hline 1 Awareness & $\begin{array}{l}1 \text { Knowledge } \\
\text { recognition }\end{array}$ & $\begin{array}{l}\text { Define... } \\
\text { List characteristics of ... } \\
\text { Name components of ... } \\
\text { Diagram... } \\
\text { List advantages/disadvantages } \\
\text { of... }\end{array}$ & $\begin{array}{l}\text { Introductory recall and recognition } \\
\text { Class presentations, discussion groups, } \\
\text { reading, watching videos, structure labo- } \\
\text { ratories. } \\
\text { Involves only recognition but with little } \\
\text { ability to differentiate. Does not involve } \\
\text { use. }\end{array}$ \\
\hline $\begin{array}{l}2 \text { Literacy } \\
\text { Strong Knowl- } \\
\text { edge }\end{array}$ & $\begin{array}{c}1 \text { Differentiation } \\
\text { in context }\end{array}$ & $\begin{array}{l}\text { Compare and contrast ... } \\
\text { Explain ... } \\
\text { Write/execute simple .... } \\
\text { Define functional capabilities } \\
\text { that are ... } \\
\text { Describe interrelations of ... to } \\
\text { related objects }\end{array}$ & $\begin{array}{l}\text { Knowledge of framework and contents } \\
\text { Differential Knowledge } \\
\text { Continued lecture and participative dis- } \\
\text { cussion, reading, team work and projects, } \\
\text { structure labs. Requires recognition } \\
\text { knowledge as a prerequisite. Requires } \\
\text { practice. Does not involve use. }\end{array}$ \\
\hline $\begin{array}{l}3 \text { Concept / Use } \\
\text { Skill }\end{array}$ & $\begin{array}{c}2 \text { Comprehension, } \\
\text { Translation, } \\
\text { Extrapolation, } \\
\text { Use of } \\
\text { knowledge }\end{array}$ & $\begin{array}{l}\text { Use ... } \\
\text { Communicate the idea of ... } \\
\text { Form and relate the abstraction } \\
\text { of ... as ..... } \\
\text { Given a set of .... } \\
\text { Interpolate/extrapolate to ..... } \\
\text { List concepts/major steps in ... }\end{array}$ & $\begin{array}{l}\text { Comprehension and ability to use knowl- } \\
\text { edge when asked/prompted } \\
\text { Requires continued lab and project par- } \\
\text { ticipation, presentation involving giving } \\
\text { explanations and demonstrations, accept- } \\
\text { ing criticism; may require developing } \\
\text { skills in directed labs. }\end{array}$ \\
\hline $\begin{array}{l}\text { 4 Detailed } \\
\quad \text { understanding } \\
\text { Application } \\
\text { Ability }\end{array}$ & $\begin{array}{c}3 \text { Application } \\
\text { Knowledge }\end{array}$ & $\begin{array}{l}\text { Search for correct solution to } \\
\ldots \\
\text { And apply it to ... } \\
\text { Design and implement a ... for } \\
\ldots \\
\text { Write syntactically correct ... } \\
\text { and/or debug ... } \\
\text { Apply the principles of ... to ... } \\
\text { Implement a ... and maintain it } \\
. . .\end{array}$ & $\begin{array}{l}\text { Selection of the Right Thing and Using It } \\
\text { without Hints } \\
\text { Semi-structured team-oriented labs where } \\
\text { students generate their own solutions, } \\
\text { make their own decisions, commit to and } \\
\text { complete assignments, and present and } \\
\text { explain solutions. }\end{array}$ \\
\hline 5 Advanced & $\begin{array}{ll}4 & \text { Analysis } \\
5 & \text { Synthesis } \\
6 & \text { Evaluation }\end{array}$ & $\begin{array}{l}\text { Develop/originate/institute... } \\
\text { Construct/adapt... } \\
\text { Generate novel solutions to ... } \\
\text { Come up with new knowledge } \\
\text { regarding ... } \\
\text { Evaluate/judge the relative } \\
\text { value of ... with respect to ... }\end{array}$ & $\begin{array}{l}\text { Identification, Use and Evaluation of } \\
\text { New Knowledge } \\
\text { An advanced level of knowledge for } \\
\text { those very capable of applying existing } \\
\text { knowledge in which denovo solutions are } \\
\text { found and utilized in solving and evaluat- } \\
\text { ing the proposed new knowledge. }\end{array}$ \\
\hline
\end{tabular}


Bloom's Taxonomy (Bloom et al., 1956), originally represented in one dimension, has been revised by Anderson and Krathwohl (2001) and now provides a two-dimensional classification with a knowledge dimension and a cognitive process dimension. The model is shown in Table 2 . The knowledge dimension proceeds from factual to conceptual, then procedural and lastly metacognitive. The cognitive processes' dimension is similar to that of Bloom's original taxonomy but replaces the nouns with verbs, as well as assimilating comprehension and synthesis into understanding and adding the creating stage. This revision of Bloom's taxonomy has six stages of cognitive development: remember, understand, apply, analyse, evaluate, and create.

Anderson and Krathwohl (2001) expand on the elements of knowledge dimension in the following way. They say that factual knowledge does not necessarily imply that the students understand at a deeper level or that they can organise and integrate that knowledge. Conceptual knowledge implies a deeper understanding that helps people to transfer something learnt in one situation to another situation (already implying some level of critical thinking). Procedural knowledge extends conceptual knowledge by incorporating knowledge of how to do something as well as being able to choose the most appropriate method or technique - another aspect where critical thinking is necessary. Finally, meta-cognitive knowledge requires "knowledge of cognition in general as well as a critical awareness of one's own cognition" (p.29).

Table 2: Revised Bloom's Taxonomy (Anderson \& Krathwohl, 2001, p.28)

\begin{tabular}{|l|l|l|l|l|l|l|}
\hline & \multicolumn{5}{|c|}{ Cognitive Process Dimension } \\
\hline Knowledge Dimension & Remember & Understand & Apply & Analyze & Evaluate & Create \\
\hline Factual Knowledge & & & & & & \\
\hline Conceptual Knowledge & & & & & & \\
\hline Procedural Knowledge & & & & & & \\
\hline Meta-cognitive knowledge & & & & & & \\
\hline
\end{tabular}

Schaefer (2006) suggests that metacognition is iterative and dynamic. It involves being able to plan, determine strategy and tactics, and assess the best way of solving a problem. Schaefer suggests that in order to become expert, we need three factors:

- declarative knowledge that may be provided by textbooks;

- procedural knowledge that involves practice and that assumes the future will be the same as the past; and

- meta-cognitive knowledge that allows us to apply our knowledge in dynamic situations where the future may not be known.

These three factors are similar to three of the four dimensions of knowledge of the Anderson and Krathwohl's revision of Bloom's taxonomy.

Metacognition allows the student to control, monitor, and regulate their own cognitive processes. By teaching students general strategies of thinking and the conditions for using these strategies, we improve the students' ability to determine what approach to use when confronted with problems. Hung and Lockard (2006) demonstrated that self reflection can significantly enhance students' problem-solving capabilities through improving the students' ability to comprehend and solve problems.

Our contention is that one should not assume that students can work at the higher levels of either the cognitive process dimension or the knowledge dimension. We contend that skills development is needed throughout the IS curriculum. In order to develop meta-cognitive skills, students need to learn to think about their own thinking and to understand the different types of higher- 
thinking skills. With the correct scaffolding, students can be encouraged to work at the higher levels of Bloom's revised taxonomy in both the knowledge and cognitive dimensions from the commencement of the first year of their IS studies.

The next section expands on the concept of scaffolding to help students develop critical thinking skills.

\section{Scaffolding}

Holton and Clarke (2006, p.131) define scaffolding as "an act of teaching that

(i) supports the immediate construction of knowledge by the learner; and

(ii) provides the basis of independent learning of the individual."

They propose that it is only by the teacher providing the scaffolding that the independent learner is supported. Walton and Archer (2004) say that scaffolding provides learners with parts of the task that may be beyond their capacity initially. This allows learners to focus on the aspects of the task that they can manage, while still keeping an understanding of the task as a whole. Scaffolding is related to Vygotsky's zone of proximal development (Rieber, 1987). Vygotsky believed that there are some problems that children can solve on their own and others that they will not be able to perform even with help. Between these two extremes, we find the problems that the child can solve with the help of the teacher, parent, or fellow students. This is true of university students too. Group activities and scaffolding provided by an expert in the form of guidance or support are therefore important in helping students to develop their ability to work independently (Jelfs, Nathan \& Barrett, 2004).

Holton and Clarke (2006) relate scaffolding in teaching to scaffolding in building construction. They say that workers are able to reach places that are otherwise inaccessible by placing a structure against the building to support them. By scaffolding students' learning and cognitive processes, lecturers are able to stimulate new learning and enable students to reach new heights. Ramsden (2003, p123) maintains that "thoughtful teachers understand that highly structured initial experiences provide students with confidence and a sense of purpose; these experiences tend to make subsequent freedoms all the more fruitful and exciting."

Scaffolding should also make tasks meaningful by building on the knowledge and abilities that learners already possess (Walton \& Archer, 2004). If scaffolding is implemented appropriately, it allows learners to gradually assimilate relevant principles and become independently responsible for their own learning (Sharma \& Hannafin, 2004). As the students progress in their learning, the scaffolding provided by the teacher is removed, but the cognitive processes learnt should remain, enabling students to apply their learning and cognitive skills independently to new problems.

\section{Scaffolding through Questioning or Prompting}

One method of scaffolding is through the use of questioning or prompting. Questions can be asked to identify the logic and/or the origin of an idea and to prompt the student into thinking about supporting or conflicting evidence or the implications of their ideas (Sharma \& Hannafin, 2004).

When students first tackle a problem we might ask questions like:

- What are the important ideas here?

- Can you rephrase the problem in your own words?

- Have you come across other problems that might help you solve this one? 
While they are working on a problem, we might ask:

- Why do you think that idea $\mathrm{X}$ is better than idea $\mathrm{Y}$ ?

- Can you justify that step?

- Are there any examples where your solution might not work?

And after they have finished the problem, we might ask:

- Can you explain your answer to the class or your group?

- Is your answer reasonable?

- Have you considered all the cases? (Holton \& Clarke, 2006, p.139).

It is evident that this type of questioning should promote critical thinking. Instead of students doing the task and skimming through the work, they are asked to stop and think about what they are doing, to evaluate their learning, and to determine whether or not their solutions would work effectively. This type of questioning can also be used to help a student to choose the most effective cognitive process to use.

\section{Scaffolding using a Framework}

Scaffolding can also be provided by giving students a "lens" or "framework" through which to study a problem (Kaste, 2004; Walton \& Archer, 2004).

Kaste (2004) for example, asked her pre-service teaching students to study teaching cases using the lens of a diverse constructivist orientation. She gave a framework based on the diverse constructivist orientation, and they used this framework to study the cases and recognise the place of the students' language, social class, and ethnicity in literacy learning. The framework formed a lens though which the students studied the teaching cases. She found that she used a lot of scaffolding in the initial cases but that her input grew less over time.

Walton and Archer (2004) provided an example that they used to help first year engineering students in South Africa evaluate whether the resources they had found on the web were of good quality and useful for them. They did this online through a fictional character called Dr Jojo, who was introduced as being a "writing consultant for rural village engineers". Dr Jojo introduced the students to a number of websites. The students were then given a framework to evaluate the websites structured around "who, why, what, when, where and for whom" questions. Examples of questions were:

- Who is the person or institution responsible for publishing this information?

- Why should I believe this person?

- What are the possible motivations behind the publication of this information?

The students then used these skills through the research phase and contributed to an online bibliography. There were significant improvements in students' referencing skills compared to previous years. Walton and Archer (2004) also found by being very clear about their evaluation criteria and providing the scaffolding for the criteria, they were able to promote more critical thinking in the students' research.

Frameworks enable students to keep the bigger picture in mind when problem solving. They help students to look at a problem from different angles, thus enabling them to reach better solutions. This makes is possible for students to think from a systems perspective as well as to evaluate their solutions critically. As they go through the course and the scaffolding is gradually removed, they will hopefully remember the lessons learnt early in the course and apply their higher level think- 
ing skills to solving the more challenging problems in the latter stages of their studies as their professional life draws closer.

\section{Scaffolding through Reflection}

Encouraging students to reflect on their own learning and thought processes is another way of scaffolding (Sharma \& Hannafin, 2004). Lecturers may initially need to give students guidelines for thinking about their thinking. Students need to be challenged to think about what they have learnt and to question their own thinking. Sharma and Hannafin (2004) asked their students to reflect on how their concept of design had changed. They then asked if it has changed, why the students felt it had changed.

If students are to learn to scaffold for themselves (using their meta-cognitive skills), they need to become aware of the scaffolding process (Holton \& Clarke, 2006). This will enable them to solve problems later without the scaffolding provided by the lecturer. Reflection can aid in this process by making students more aware of the way in which they have been guided through the process of solving a particular problem. Reflection encourages deep learning and the application of the skills learnt to future problems.

\section{Developing Critical Thinking through the Curriculum}

\section{A Foundation Subject in Reasoning and Critical Thinking}

Driskill, Lewis, Stearns and Volz (1998) discuss the problems that first year students have in understanding the difference between knowing the material and being able to regurgitate information, and the ability to be able to argue a point and explain their reasoning. They say that even after receiving feedback on examinations, students have difficulty recognizing the difference between a "memory dump" and giving an answer that explains a concept and establishes the connections between facts. Metacognition helps students to understand their own thinking.

Krishna Rao (2005, p.174) proposes that teaching thinking skills explicitly will facilitate the following:

- Students will be able to reflect on different types of thinking skills and which ways of doing things are most appropriate to practise;

- Students can practise and build habits of thinking effectively; and

- Students can become familiar with what type of thinking is appropriate or called for.

Sharma and Hannafin (2004, p.183) suggest that "an understanding of one's own thinking, learning and processes may be the first step in allowing students to engage in thinking, learning and dialogue with others." We agree with Sharma and Hannifin that there is a need for students to develop these skills and that scaffolding may help in this process. Our approach introduces the students to different types of thinking skills in an introductory, foundation subject and then practises and enlarges upon these throughout the curriculum.

This part of the paper will give a brief overview of the subject as it is taught at ACU National with more specific information on some of the topics presented in the examples that follow. These examples will also show how students' critical thinking can be developed from the foundation subject through the rest of the curriculum.

The subject Reasoning and Critical Thinking for IS Professionals introduces first year IS students at ACU National to various types of thinking. In particular, students learn about critical thinking, systems thinking, analytical thinking, reflective thinking, and consequential thinking and how these types of thinking skills are useful in IS. 
To improve students' thinking abilities in the context of the IS curriculum, students are given an assignment where they are required to write an essay on a controversial IS-related topic using the knowledge and skills associated with critical thinking that they have been taught in lectures and workshopped during tutorials. As well as being taught about claims, premises, conclusions, and good and bad arguments, students also learn to structure their own arguments and to use scholarly publications to support their arguments. The independent use of these skills is necessary when students write their essay. Students are also given the opportunity to critically analyse both their own and other students' written work in an anonymous peer review process. Scaffolding, in the form of prompts, is used to help the students understand the processes of writing an essay, critical analysis, and reflection. These prompts help students to put into action and to think about what they have learnt about thinking in class. More detail of an essay assignment used is given later in this paper.

Students explore de Bono's (1976) thinking skills techniques and are shown how to use these in systems analysis and design. These skills include PMI (Plus, Minus, and Interesting), where students are asked to consider what is positive (Plus), negative (Minus), and interesting about a proposed scenario; CAF (Consider all factors), where students learn to look at a situation from different points of view and to consider all the factors that might influence the development of an information system. Students are also taught to look at the bigger picture using systems thinking and are introduced to the soft systems methodological tool of rich pictures (Monk \& Howard, 1998) to support this type of thinking. This is expanded on later in the paper.

Another aspect of the subject integrates analytical and critical thinking into the task of algorithm design, a skill students will require when they study programming later in their course. In the Reasoning and Critical Thinking subject, we teach students how to break a problem down into parts using analytical thinking. We also ask students to evaluate algorithms and to debug using critical thinking skills. An example of this is presented later in this article.

Table 3: Comparison after moving subject to the first semester (Davis, Thomas \& Kazlauskas, 2006, p.43)

\begin{tabular}{|c|c|c|c|c|c|c|}
\hline & & & $\begin{array}{l}2003 \\
N=85\end{array}$ & $\begin{array}{l}2005 \\
\mathrm{~N}=56\end{array}$ & $\mathrm{t}(139)$ & $\mathrm{p}$ \\
\hline \multirow[t]{2}{*}{ Q12 } & \multirow{2}{*}{$\begin{array}{l}\text { This unit has helped me or will help me } \\
\text { in my studies }\end{array}$} & Mean & 3.82 & 4.30 & \multirow{2}{*}{2.93} & \multirow{2}{*}{0.004} \\
\hline & & S.D. & 1.01 & 0.85 & & \\
\hline \multirow[t]{2}{*}{ Q13 } & \multirow{2}{*}{$\begin{array}{l}\text { This unit has helped me or will help me } \\
\text { in my daily life }\end{array}$} & Mean & 3.21 & 3.98 & \multirow{2}{*}{4.29} & \multirow{2}{*}{0.000} \\
\hline & & S.D. & 1.01 & 1.09 & & \\
\hline \multirow[t]{2}{*}{ Q14 } & \multirow{2}{*}{$\begin{array}{l}\text { This unit will help me when I get into the } \\
\text { IS industry }\end{array}$} & Mean & 3.89 & 4.14 & \multirow{2}{*}{1.49} & \multirow{2}{*}{0.139} \\
\hline & & S.D. & 1.00 & 0.92 & & \\
\hline \multirow[t]{2}{*}{ Q15 } & \multirow{2}{*}{$\begin{array}{l}\text { This unit has helped me or will help me } \\
\text { when reasoning with others }\end{array}$} & Mean & 3.54 & 4.23 & \multirow{2}{*}{4.20} & \multirow{2}{*}{0.000} \\
\hline & & S.D. & 1.06 & 0.76 & & \\
\hline \multirow[t]{2}{*}{ Q16 } & \multirow{2}{*}{$\begin{array}{l}\text { This unit has helped me or will help me } \\
\text { to analyse other people's points of view } \\
\text { in a more effective manner }\end{array}$} & Mean & 3.81 & 4.34 & \multirow[b]{2}{*}{3.25} & \multirow[b]{2}{*}{0.001} \\
\hline & & S.D. & 1.04 & 0.77 & & \\
\hline
\end{tabular}

Davis, Thomas and Kazlauskas (2006) report on an action research project that was carried out in the first three years of running the subject. During this time, the subject content was refined and integrated closely to the Information Systems discipline, and the subject was moved from the second semester of the first year to the first semester of the first year so that it formed the foundation for the rest of the degree. Both the quantitative and qualitative data reported in the article showed that the students' perceptions of the subject improved after the move from second to first semester. Table 3 compares the means of some of the quantitative questions where students were asked to evaluate their perceptions of the usefulness of the subject for their studies, daily life, IS indus- 
try, ability to express themselves when reasoning with others, and their ability to analyse other people's points of view. A five-point Likert scale was used. There was a significant improvement in all but one of these aspects. Although Question 14 did not significantly increase, it did have the strongest positive view in 2003 and showed an increased positive view in 2005.

Some of the first year students, in particular some of the international students, mentioned how the approach used helped them to gain confidence:

"As a $1^{\text {st }}$ year we are bit nervous. I believe this course helps to get confident. Overall change of way - like before I thought uni is very hard, I can't study as my English is not

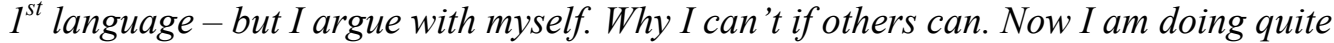
well. (Punctuation inserted.)

Even though the students were specifically asked to reflect on both the positive and negative factors of the subject, by 2005 the number of negative comments had almost disappeared. Of the 52 students who answered the question of what they liked LEAST about the subject, 15 students $(29 \%)$ remarked that they enjoyed everything or that there was nothing that they did not like. The most common least-liked aspect of the subject was the section on algorithms (6 students $-12 \%$ ), closely followed by the early start (8am) with four students $(8 \%)$ saying this. One specific statement was the following:

"There is nothing that I can put in this category because I thoroughly enjoyed every aspect of this subject. I wish that every subject I studied at university was as interesting and enjoyable as this one."

More detail on this research can be found in Davis, Thomas and Kazlauskas (2006).

Table 4: Examples of development of Critical Thinking skills through the curriculum

\begin{tabular}{|l|c|c|l|l|}
\hline $\begin{array}{l}\text { Critical Thinking } \\
\text { Skill }\end{array}$ & $\begin{array}{l}\text { Year } \\
\text { Level }\end{array}$ & Semester & Subject Name & Scaffolding / Metacognitive Skills \\
\hline \begin{tabular}{l} 
Critical and $\begin{array}{l}\text { Analytical thinking } \\
\text { for Programming }\end{array}$ \\
\cline { 2 - 5 }
\end{tabular} & 1 & 1 & $\begin{array}{l}\text { Reasoning and Critical } \\
\text { Thinking for IS Professionals }\end{array}$ & $\begin{array}{l}\text { Framework } \\
\text { Prompting } \\
\text { Meta-cognitive skills developed }\end{array}$ \\
\cline { 2 - 5 } & 2 & 1 & Programming Techniques 1 & Peer and self review used \\
\cline { 2 - 5 } & 2 & 1 & Database Design & $\begin{array}{l}\text { Peer and self review used } \\
\text { Most scaffolding removed }\end{array}$ \\
\hline $\begin{array}{l}\text { Problem Solving for } \\
\text { Systems Analysis \& } \\
\text { Design }\end{array}$ & 1 & 1 & $\begin{array}{l}\text { Reasoning and Critical } \\
\text { Thinking for IS Professionals }\end{array}$ & $\begin{array}{l}\text { Questions and Prompting } \\
\text { Meta-cognitive skills developed }\end{array}$ \\
\cline { 2 - 5 } & 1 & 2 & $\begin{array}{l}\text { Systems Analysis and De- } \\
\text { sign }\end{array}$ & Questions and Prompting \\
\cline { 2 - 5 } $\begin{array}{l}\text { Writing Essays that } \\
\text { include argument }\end{array}$ & 1 & 1 & $\begin{array}{l}\text { Reasoning and Critical } \\
\text { Thinking for IS Professionals }\end{array}$ & $\begin{array}{l}\text { Questions and Prompting } \\
\text { Reflection } \\
\text { Meta-cognitive skills developed }\end{array}$ \\
\cline { 2 - 5 } & 1 & 2 & $\begin{array}{l}\text { Systems Analysis and De- } \\
\text { sign }\end{array}$ & Prompting \\
\cline { 2 - 5 } & $2 / 3$ & & Ethics and Informatics & $\begin{array}{l}\text { Self Review } \\
\text { Reflection }\end{array}$ \\
\hline
\end{tabular}

Table 4 gives an indication of the different higher-order thinking skills that are being developed in this subject and where they are used within the Information Systems course. The specific way in which the skills are developed is explained in the examples in the sections that follow. This is not an exhaustive list of how the skills could be developed in other subjects or topics. These are examples from subjects that are taught by one or more of the authors. They have been chosen to 
show how scaffolding can be used to help students develop their thinking skills throughout the IS curriculum. The examples show how scaffolding is used in the first year and reduced in the second, leading to the students working independently in their final years where students have a greater understanding their own reasoning and thinking.

\section{Examples of Critical Thinking Skills Development in Programming}

This section contains a number of examples that the authors have selected to demonstrate the manner in which scaffolding can be used to support the development of students' thinking skills.

\section{From analytical and critical thinking skills to algorithms}

As stated earlier, Reasoning and Critical Thinking for IS Professionals firstly introduces the student to how their thinking skills can be used to analyse systems, to determine how a computer system will interact with the rest of an organisation, to solve problems, and to develop algorithms.

Assume that you have the statement:

No-one is allowed to do the subject INFO117 unless they are enrolled in the BIS degree.

This is a typical critical thinking problem, where students might be asked to make deductions, given that the statement is true. For example, they might be asked what you can deduce about students enrolled in the INFO117 subject or what can we deduce if we know someone is enrolled in the BIS degree.

If we wanted to incorporate this condition in a computer program, what algorithm can we write? Many students will do the following:

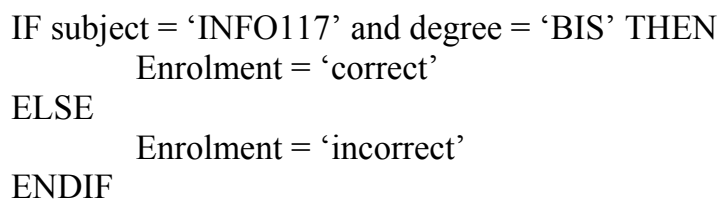

By applying critical thinking skills, students can be guided through the thinking process to see what they can deduce from this statement. The critical thinking skills will help them to determine that:

All students in the INFO117 subject must be enrolled in the BIS degree.

Students enrolled in INFO117 cannot be enrolled in any degree except the BIS degree.

The statement does not tell us anything about any subject except the INFO117 subject.

This in turn should help students to create the following set of IF statements:

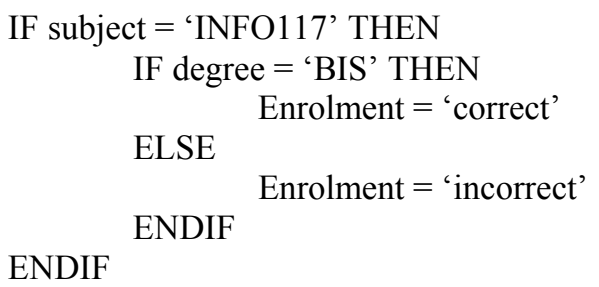

Note: At ACU National, the Reasoning and Critical Thinking subject is taught BEFORE the first programming subject so we have to keep the ideas of variables and algorithms fairly simple.

Figure 1: From critical thinking to algorithm design 
The example given in Figure 1 shows, through the use of scaffolding, how critical thinking supports algorithm development. This particular problem illustrates how critical thinking skills can be used to develop IF statements that produce the correct results.

An example of part of a more complex algorithm exercise is given in Figure 2 where scaffolding is provided in the form of a framework for testing the algorithm. This exercise aims to help students develop their skills of thinking critically about programs that they might be required to develop later in their studies. Students learning to program often tend to focus on the syntax of the problem rather than ensuring that their program is correct. They also often seem to think that if the program runs and gives an answer, then that answer is correct. In this example, the framework requires the student to: create the test data ensuring all eventualities are catered for, work out the output expected, then test the algorithm, determine if the expected output matches the output achieved, and correct the logic if there is a problem. The example given in Figure 2 includes a reflective question at the end.

Suppose that you want to make sure that people use passwords that are not easy to guess. You devise the following set of rules for checking new passwords:

- Passwords must be at least 6 characters long

- Passwords must include at least one number

- Passwords must include at least one letter

The input to the algorithm should be the new password, one character at a time, followed by a "/". The output should be the words "Thank you for a valid password" or an error message that tells the person what the problem with their password is.

..... [Sample code with errors in it inserted here $]. . . .$.

i. $\quad$ Create 4 sets of test data for the above program

(Make sure that the four sets of data include some passwords which are correct and some with errors.)

Explain why you have chosen these particular 4 passwords for testing.

ii. List the output that you would EXPECT for each of your test data passwords.

iii. Take each of your test data through the pseudocode given above and determine the actual output for each.

iv. Is the pseudocode logically correct? If it is not correct then explain how you should go about correcting it.

v. Why should you determine the output you expect from the data before determining the actual output?

Figure 2: Algorithm example of critical thinking

As can be seen in Figure 2, the example asks the students to create test data and to explain why they have chosen the test data. This forces students to think about what types of test data they are creating and why they need to have different sets of test data. Students are then asked to determine the output they expect from the data. This once again reinforces the need for thinking about what the answer might be BEFORE going into the testing of the algorithm. Anecdotal evidence suggests that this is something that many students never seem to learn. Only after writing down the answer they expect, are students asked to trace the algorithm and generate answers from their 
test data. This scaffolds the students' thinking, helping them to develop a cognitive and practical framework to apply to programming in the future.

The example in Figure 2 and others like it are fairly complex when one considers that these students only do 12 hours of algorithm design in this subject. During that time, students are expected to develop an understanding of loops, IF statements, variables, and many other concepts. We have found that while the students find this difficult, many of them comment later in the course on the value of this foundation subject when they were studying programming.

"The aspects which have helped me the most in my studies would easily be the critical thinking and analytical thinking involved in the unit. This has helped me a great deal during the year, mainly with programming techniques. More than anything, it has helped me to analyze the problem and fix it."

Tasks such as that given in Figure 2 can also be done in pairs so that students critically evaluate one another's algorithm designs. The advantages of a pair approach such as this is supported by the findings of McDowell, Werner, Bullock \& Fernald (2006) where the findings revealed significant improvement in individual programming skills as well as more core problem-solving skills in both the short term as well as the longer term. This example comes from the foundation subject in reasoning and critical thinking, which is taught before the students study programming.

\section{Programming and critical thinking}

Since the early years of programming, researchers have been studying the link between critical thinking and programming. Much of this research has focused on whether or not programming can help a student to develop critical thinking skills. An early article by Stalnaker in 1965 investigated this relationship and subsequent researchers have continued to study this. While some of the studies found a minor relationship (Norris \& Jackson, 1992), many of them found no significant relationship between learning programming and improving critical thinking skills (Grant, 2003; Mayer, Dyck, \& Vilberg, 1986).

Our approach teaches students generic critical thinking skills first and then the algorithm design and programming skills. Building on our experience in the Reasoning and Critical Thinking unit, we suggest that as students progress through the course, they develop their ability to think critically by evaluating their programming tasks. For example, one might introduce a peer-review process where students are given two different programming tasks for homework and are expected to develop a program in one and set up test data for the other. Students must then test each others' programs and together come up with the correct solutions for each task. This type of activity aims to develop students' critical thinking skills, to allow them to be active learners, and to improve their interpersonal and communication skills. It also prepares students for work in an agile development environment using pair programming techniques. The scaffolding is provided by the design of the task including the peer review process.

\section{SQL and critical thinking}

Programming in SQL is another area where the explicit use of critical thinking skills can be helpful in developing students' abilities. To give an example, students might be asked to:

Write SQL statements to do the following:

i. List the names, addresses and phone numbers of all customers that have bought product 1234 in the past six months.

ii. Delete all the order lines for order 4444 and then delete order 4444. 
There is no doubt that doing exercises like this give the students valuable practice and help them to develop their SQL skills. But how can students' critical thinking skills and SQL be synergistically enhanced? Figure 3 gives an example of how this might be achieved.

In an introductory SQL subject, we could use the following approach to scaffolding the students thinking to
help them to learn the SQL. This also uses students' systems thinking skills and makes connections be-
tween the knowledge they have acquired in different areas:
i.
Product 1234 has been recalled due to a fault. We need to contact all the customers who have
bought this product in the past six months.
a. What information do we need to get about the customers?
b. Where is the information stored about the customers and where is the information stored on
who has bought which products? List the tables and then determine how these tables are
linked through their foreign keys.
c. Write one SQL statement that will extract the information needed into a list form.
Order 4444 has been cancelled and needs to be deleted from the database.
a. Delete order 4444 from the ORDER table.
b. You should have an error message - what is the error message and why did it occur? (For-
iign key problem with the ORDERLINE table. Bracket not part of the question - merely for
clarification)
c. Write the SQL statements to delete order 4444 entirely without getting the error.
d. If we delete an order and its order lines, are there any other parts of the database that might
need to be updated to keep the database in sync? (This might refer to updating of accounts or
stock levels - depends on the database structure.)

Figure 3: An SQL example

The questions in Figure 3 help the students to scaffold their thinking and to work out how to handle problems. In these examples the knowledge of how foreign keys work has been integrated into the problem. The students need to read and understand error messages instead of asking a tutor to help them solve any difficulties they experience as a first response. By including problem solving of the foreign key issue within the solution of the SQL problem, the students apply their new knowledge as well as practising and extending their ability to think critically by evaluating their own work. The questions help the students to work at the higher-levels of Bloom's taxonomy, namely, analysis, evaluation, and creation. Students are also required to think of how different parts of a system might affect one another and apply this in the last part of the question.

As students' abilities to think critically improve, they have a reduced need for the scaffolding and therefore the questions lecturers ask of them can become more applied and more complex. Lecturers can expect more of the students' thinking. These skills and processes prepare students for tasks like a capstone project, where they have to understand the bigger picture and use systems thinking to ensure that their system works effectively.

\section{Problem-solving Techniques in Systems Analysis and Design}

\section{From problem solving to systems analysis and design}

The students are introduced to de Bono's (1976) problem solving techniques in the Reasoning and Critical Thinking unit. We describe the problematic scenario of voting in a developing country in Africa and ask students how technology could be used to improve this situation. We take the students through different problem-solving techniques. They need to Consider all Factors (CAF), work out what is positive, negative, and interesting using the PMI (Plus, Minus, and Interesting) technique, Brainstorm ideas for a solution, evaluate those ideas using the SCAMPER technique (Substitute, Combine, Adapt, Modify, Put to other uses, Eliminate, and Rearrange), 
then evaluate the consequences and results of any solution using the $C \& R$ technique. Students then determine what type of solution would improve the voting process in the African country.

After students learn these techniques, they use them as they learn systems analysis and design techniques. The students are introduced to systems thinking and Rich Pictures (Monk \& Howard, 1998). Instead of just asking students to draw a rich picture, we scaffold the task giving the prompts to ensure that they use some of the problem-solving techniques that they have learnt previously. An example of this is shown in Figure 4.

Students are given the scenario including information from several stakeholders with different views and concerns. Instead of asking students just to construct a rich picture, the task is scaffolded using prompts. Students are asked to:

- List the stakeholders involved in the scenario.

- List the factors to be considered when designing the information system for the Scenario. Use the CAF (Consider All Factors) technique.

- Describe plus, minus, and interesting factors about implementing a computer system rather than doing things manually. (Use the PMI technique).

- Explain the criteria to be used to measure whether or not their solution was successful.

- Draw a rich picture to show how the Scenario works and the concerns of the people affected by the system.

- Reflect on how they used the answers in the first part of the exercise to enable them to draw the rich picture.

Figure 4: Example of systems thinking

\section{Systems analysis and design projects}

These methods and techniques of systems thinking and higher level problem solving can be used in students' formal study of systems analysis and design where students have to develop IS projects. If the students only learn the procedures for drawing rich pictures, their learning is confined within the procedural knowledge dimension and the analysing and applying cognitive dimensions of the revised Bloom's taxonomy. With the addition of the scaffolding, students are able to reflect about how to go about thinking about the problem. This raises students' level of knowledge to the meta-cognitive level.

As they learn to model systems, whether using UML or more traditional techniques, they should be able to draw on the techniques learnt in the foundation unit.

By the time they get to the capstone project in the third year, the scaffolding has been removed and the students are left to apply the techniques for themselves.

\section{Developing Students' Ability to Write}

\section{Learning to write an argument}

The IS 2002 curriculum calls for lecturers to help students develop their written communication skills (Gorgone et al., 2002). Anewalt (2003) calls for the integration of writing components in computer courses. She stresses that universities have a responsibility to business to provide exposure to good professional practice and, in particular, good writing.

Learning to write a good argument is an important part of academic writing at university. Writing tasks help students develop their ability to analyse articles, think critically about them, evaluate arguments put forward by others, to determine and then write about their own point of view, substantiating that view with good reasoning. 
As part of the Reasoning and Critical Thinking subject, students are taught about constructing and evaluating arguments. These skills are contextualised within the IS discipline as much as possible. For example, students might be given a pseudo argument between users of an IS system and be asked to evaluate the arguments and determine what can be concluded from these arguments and why.

As an example of how we help students to develop their writing skills, we will describe the task related to the topic of Internet Governance that was used in 2005 within the foundation subject. In many instances students would be given the topic in Figure 5 as an introductory essay expecting that the students would understand what is needed and would write the essay appropriately.

Should the internet be governed?

The internet and World Wide Web have grown haphazardly since their invention. They have provided an almost instant means of communication between all nations and peoples of the world. There are, however, questions of whether or not the internet should be allowed to continue its development in such an uncontrolled manner. As a result 'internet governance' has become an issue for discussion and debate. Write an essay discussing this topic in not more than 1000 words.

Figure 5: The essay topic to be scaffolded for use in a first-level subject

Our approach does not assume that students can automatically do this at a tertiary level. So we provide scaffolding to support the development of critical thinking skills and written communication skills. We break down the assessment into a series of tasks that students need to carry out in order to develop and write a well-supported argument. As will be seen below, a peer review exercise has been incorporated into this process to further enhance students' critical thinking abilities.

\section{Preparatory tasks}

Students were given references to four articles that took different views of the topic. Some articles argued for Internet Governance and others against. Students were then asked to find AT LEAST another two articles of their own on the topic. When they had all their articles they were required to write the references for those articles in APA format - both for in-text citation and for the list of references at the end of the article. After reading the articles, students were required to underline arguments for and against the implementation of Internet Governance. Having identified reasons for and against internet governance, students were required to decide, then state, their own view on the matter. Finally, students wrote the first draft of a short essay using additional information about how to structure the essay including an introduction that told the reader what was meant by Internet Governance. They then stated their position either for or against Internet Governance, substantiating that view using arguments and counter-arguments from the articles they had read. The essay was expected to finish with a strong conclusion.

\section{Evaluation of the draft}

The students brought their draft essays to class for a peer-review process. It is at this stage that we taught students more about plagiarizing and citations. Acting as anonymous peer reviewers, students were given pro-formas containing guidelines and a questionnaire to fill in about the preparatory tasks completed by one or two of their fellow students. In particular, students were asked to evaluate the essay based on general aspects of essay writing: clarity of writing, citing sources, referencing, and quality of the introduction and conclusion. In addition, students evaluated whether their peer had constructed a good argument, whether they had substantiated that argument with good quality supporting journals, and whether they had considered and argued against any counter arguments. Students determined whether their peer had demonstrated any bad habits such as exaggerating, using vague claims, using common meaningless phrases, or using claims 
which could not be substantiated. These peer reviews and participation in the peer review process provided scaffolding that challenged students to think critically about their work.

\title{
Preparing the final version and reflection
}

Lastly, students were asked to review and improve their own assignments. Students were also required to reflect on and write about what they had learnt through the peer-review process. Such reflection helped students to further develop their meta-cognitive skills, to gain insight into their own learning, and what this experience could mean for them in the future. Many of the students' reflections showed that they appreciated having the opportunity to learn in this way. One example is given below:

\begin{abstract}
My experience on doing this assignment was truly positive. It allowed for a constructive way of debating an informative topic. The evaluation process helped me to improve my report and present it in a more comprehensive state. I have learnt that proof reading your work in most cases it's (sic) not enough and that a reader-review can help stimulate a better report which is very helpful. ... learnt much about the way an argument and rebuttal can operate and how conclusive evidence is so important in the subject matter of a report....Reviewing somebody else's assignment was also a big bonus. It allowed the class to experience the report writing process from a reader's point of view and gave them extra information and ideas to help them construct their own report better.
\end{abstract}

In the first semester of 2006, we experimented with a group writing task to see if a carefully scaffolded group task was beneficial to the development of students' critical thinking abilities. Our first take on this task used the same approach as carried out previously: students prepared their own answers to the questions. The peer-review activity then gave students the opportunity to improve their answer and to revise it as their individual 'best' answers for presentation to a small group of other students. In the next step, students engaged in the preparation and publication of a single document that integrated their individual best answers into an even better group answer. The final step required students to review the de-identified group answers and identify the class 'best', and the 'nearly the best' answers as well as a third answer that was 'up with the best'. In order to prevent students handing in the work of just one student, they were required to hand in their individual drafts with the final assignment. Each student reflected in writing on what they have learnt. This task reinforced the role of critical thinking in the process that van Aalst (2006) referred to as idea improvement. Once again, students' comments described their appreciation of the benefits of this novel approach.

\begin{abstract}
I was a bit nervous in showing some of my answers because I thought to myself that everyone else would show good answers and I would show wrong, general answers. After comparing with the other group members' answers and opinions, I thought my answers were good, and I thought to myself that I really did think hard to come up with my answers. I was very comfortable with sharing my answers and views with my group. We all came up with good solid answers, opinions and points of view ... we loved sharing new ideas and assumptions with each other every time we talked about it. We took ideas from each other together to come up with our best answer to the best of the group's ability.... Since this assignment, I have found out and learnt that I have more of a creative and critical thought of mind and I can use this advantage in my other studies which will help me a great deal. ... From doing this assignment, I have gained confidence in being more direct and confident in showing my work to other people, and further developed my skill in working with other people.
\end{abstract}

\section{Essay writing later in the curriculum}

In the second semester of 2006, students in the Bachelor of Information Systems, who had completed Reasoning and Critical Thinking for IS Professionals in the previous semester, along with a group of students undertaking the Bachelor of Business with either the accounting or the human 
resource management major, undertook the subject Systems Analysis and Design (SAD). The Bachelor of Business students had not studied Reasoning and Critical Thinking but were required to undertake SAD as part of the core subjects in their major (Accounting Information Systems or Human Resource Information Systems). One of the assessment items in the subject consisted of the students undertaking research into the impacts of changes in their chosen professional area on the approach(s) taken to the analysis and design process (see Figure 6).

Historic measures of success in information systems development have been the ability to meet user requirements, on time and on cost. Over time, various approaches to the analysis and design of information systems have evolved or new approaches developed to address the changing characteristics of information systems with a view to improve the ability to meet these measures of success.

In the context of your particular discipline area, identify a significant change in requirements that might impact on the type of approach taken to the analysis and design of a relevant information system and write a research essay discussing both the change and the impact on the approach.

In undertaking your research, you are required to review the current literature on your specific topic and select some combination of SIX professional/technical and research articles from those you reviewed.

On the basis of the selected articles, prepare a research report of approximately 1500 words, addressing your topic and following the guidelines outlined in the Submission Requirements to include:

The report should begin with an abstract that introduces the reader to the topic along with a brief description of what will be presented in the remainder of the report. It should be approximately 200 words in length (included in the total word count).

The report's body should clearly identify and provide a reasonable analysis of the findings from the selected literature.

The report's conclusion should act as both a summary and as a mechanism for identifying the potential impacts of the topic on future directions in information systems development.

\section{Figure 6: The essay topic given to students in SAD}

One can see here that, while students are prompted as to what to write and what is needed, most of the detailed form of scaffolding provided in the Reasoning and Critical Thinking for IS Professionals essay assignment has been removed. Students are expected to be able to use the skills learnt previously.

Marking of the assessment based on the criteria set out in the assignment protocol was undertaken by an independent staff member. Written comments during the moderation process revealed what had been reported as anecdotal in Thomas, Davis, and Kazlauskas (2004). While the marker was unaware of any differences between the previous studies of the students, one of the comments when the marks were originally submitted was ... Have they (referring to the Bachelor of Information Systems students) had you for something else? The marker had noticed that the submissions of these students, who had completed the Reasoning and Critical Thinking subject previously, demonstrated superior skills in relation to the gathering of information, the analysis of that information, and their ability to more reasonably articulate the outcomes.

Scaffolding in the form of prompts and questions is also used by one of the authors for an essay in the Ethics and IT unit studied in the second or third year of the Bachelor of Information Sys- 
tems degree. The students are asked to write an essay on an IT ethical issue. They are then given the following prompts that act as scaffolding:

The essay should address the following:

- A brief introduction to the topic

- What are the main ethical arguments involved in the issue as it relates to Information Technology?

- What ethical principles could be applied to this topic - Relate this to the ethical principles that you have learnt. How would the different ethical theorists view the topic?

- How would the Australian Computer Societies' code of ethics influence decisions that you might make on this particular topic?

- What is your view on the topic? Present your view together with supporting arguments for that view.

- Conclusion - draw conclusions from your essay

Instead of peer review, the students are asked to self-review their essay and reflect on that review. This helps to develop the skills that they will need to write in the future and to critique their own writing.

\section{In Conclusion}

The previous section has given a few examples of how tertiary educators can use scaffolding to help students develop their critical thinking skills while learning IS. The method used a foundation unit to help students learn critical thinking, meta-cognitive and problem solving techniques.

Current calls for students' critical thinking abilities to be developed during university studies assume that many students do not possess these skills at a professional level when they leave their tertiary studies. As part of our ongoing action research into the development of IS students' thinking skills, we have developed an informed understanding of the role of scaffolding in the construction of assessment and other tasks. This paper shows how giving the students a firm foundation in critical thinking skills and an awareness of their own meta-cognitive abilities, can be used throughout the curriculum.

Our aim in using these systematic approaches to task construction within the IS undergraduate curriculum is to ensure that by their final year, IS students are able to independently discuss, give their views and write an argument without needing the scaffolding. Such skills will stand them in good stead when they graduate and join the IS profession.

\section{Acknowledgement}

We wish to acknowledge and express our gratitude to Academic Skills Advisors, Sophie Gimel, Leignana Thornton, Jo Reidy and Nancy Reed for their considerable input into the development of and support during the conduct of the writing tasks.

\section{References}

Anderson, L. W., \& Krathwohl, D. R. (Eds.) (2001). A taxonomy for learning, teaching and assessment: A revision of Bloom's taxonomy of educational objectives. New York: Longman. 
Anewalt, K. (2003). A professional practice component in writing: A simple way to enhance an existing course. Journal of Computer Sciences in College, 18(3), 155-165. Consortium for Computer Sciences in Colleges.

Ayersman, D. J., \& Reed, W. M. (1995-1996). Effects of learning styles, programming, and gender on computer anxiety. Journal of Research on Technology in Education, 28(2), 148-161.

Bloom, B. Englehart, M. Furst, E., Hill, W., \& Krathwohl, D. (1956). Taxonomy of educational objectives: The classification of educational goals. Handbook 1: Cognitive Domain. New York, Toronto: Longmans, Green.

Davis, T., Thomas, T., \& Kazlauskas, A. (2006). What were you thinking? Empowering tomorrow's professionals today. International Journal of Pedagogies and Learning, 2(1), 34-46.

de Bono, E. (1976). Teaching Thinking. London: Maurice Temple Smith Ltd.

Driskill, L., Lewis, K., Stearns, J., \& Volz, T. (1998, April). Students' reasoning and rhetorical knowledge in first-year chemistry. Language and Learning across the Disciplines, 2(3), 3-24.

Fagin, B., Harper, J. Baird, L., Hadfield, S., \& Sward, R., (2006). Critical thinking and computer science: Implicit and explicit connections. Journal of Computing Sciences in Colleges, 21(4), 171-177.

Gorgone, J. T., Davis G. B., Valcich, J. S., Topic, H., Feinstein, D. L. \& Longenecker, H. E., Jr. (2002). Model curriculum and guidelines for undergraduate degree programs in information systems. Association of Information Systems, Available from URL: http://www.aisnet.org/Curriculum/

Grant, N. S. (2003). A study on critical thinking, cognitive learning style and gender in various information science programming classes, Proceedings of CITC4'03, October 16-18, Lafayette, Indiana, USA, pp 96-99.

Holton, D., \& Clarke, D. (2006). Scaffolding and metacognition. International Journal of Mathematical Education in Science and Technology, 17(2), 127-143.

Hung, W., \& Lockard, J. (2006). Students' perception of knowledge activation on a guided collaborative problem solving organizer. Proceedings of the $7^{\text {th }}$ Annual Conference on Learning Sciences, p.270276.

Jelfs, A., Nathan, R., \& Barrett, C. (2004). Scaffolding students: Suggestions on how to equip students with the necessary skills for studying in a blended learning environment. Journal of Educational Media, 29(2), 85-96.

Jones, H. M. (1997). An introduction to critical thinking. Riverwood, NSW, Australia: Social Science Press.

Kaste, J. (2004). Scaffolding through cases: Diverse constructivist teaching in the literacy methods course. Teaching and Teacher Education, 20, 31-45.

Krishna Rao, M. R. K. (2005). Infusing critical thinking skills into content of AI course. Proceedings of ITiCSE'05, June 27-29, Mone de Caparica, Portugal, pp173-177.

Mayer, R. E., Dyck, W., \& Vilberg, W. (1986). Learning to program and learning to think: What's the connection? Communications of the ACM, 29(7), 605-610.

McDowell, C., Werner, L., Bullock, H. E., \& Fernald, J. (2006). Pair programming improves student retention, confidence, and program quality. Communications of the ACM, 49(8), 90-95.

Monk, A., \& Howard, S. (1998). The Rich Picture: A tool for reasoning about work context. Interactions, March + April, 21-30.

Norris, C., \& Jackson, L. (1992). The effect of computer science instruction on critical thinking skills and mental alertness. Journal of Research on Computing in Education, 24(3), 329-337.

Pascarella, E. T., \& Terenzini, P. T. (1991). How college affects students: Findings and insights from twenty years of research. San Francisco: Jossey-Bass.

Ramsden, P. (2003). Learning to teach in higher education (2nd ed.). London: Routledge Falmer. 
Rieber, R. W. (Ed.) (1987). The collected works of L. S. Vygotsky. Volume 5: Child Psychology. New York: Kluwer Academic.

Schaefer, R. (2006). A critical programmer searches for professionalism. ACM SIGSOFT Software Engineering Notes, 31(4), 1-17.

Sharma, P., \& Hannafin, M. (2004). Scaffolding critical thinking in an online course: An exploratory study. Journal of Educational Computing Research, 31(2), 181-208.

Stalnaker, A. W. (1965). The Watson-Glaser critical thinking appraisal and programming performance. Proceedings of the Third Annual Conference of Special Interest Group on Computer Personal Research, pp.75-77.

Thomas, T., Davis, T., \& Kazlauskas, A. (2004). Critical thinking and reasoning for information systems. Journal of Issues in Informing Science and Information Technology, 1, 115-131. Available at http://articles.iisit.org/025thoma.pdf

Van Aalst, J. (2006). Rethinking the nature of online work in asynchronous learning networks. British Journal of Educational Technology, 37(2), 279-288.

Walton, M., \& Archer, A. (2004). The web and information literacy: Scaffolding the use of web sources in a project-based curriculum. British Journal of Educational Technology, 35(2), 171-186

\section{Biographies}

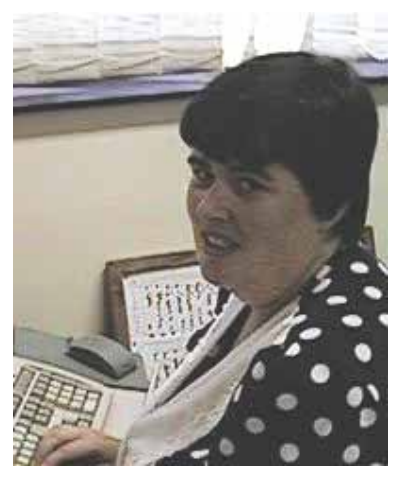

Theda Thomas is currently the Associate Dean (Teaching, Learning and International) for the Faculty of Arts and Sciences at ACU National. Until the end of 2006, she was a Senior Lecturer in Information Systems. Her research interests are in Information Systems Education, first year learning and the integration of the development of graduate attributes into curricula.

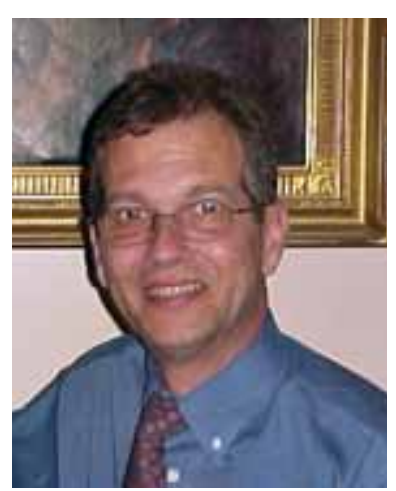

Tim Davis is a senior lecturer in School of Business and Informatics (QLD) He has over 19 years of tertiary academic experience in the information systems and business disciplines and two of his special research interests are in learning technologies and self-directed learning.

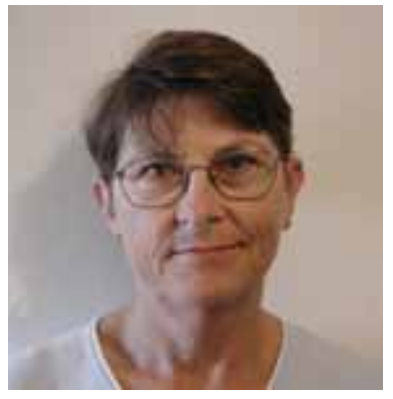

Alanah Kazlauskas is a lecturer in the School of Business and Informatics (NSW) at ACU National. Her research interests include the first year in higher education, professional development and online teaching and learning. 